out well the erythroblastic reaction, and that when the nucleated red cells in the marrow are increased there is also an increase in the lymphoid cells from which they are derived. J. S. Dunn (Glasgow), in a paper on the Oxydase Reaction in Myeloid Tissues, demonstrates that the synthesis of indophenol from alpha-naphthol and dimethyl-paraphenylendiamin is produced by neutrophile and eosinophile leucocytes, and less rapidly by large hyaline leucocytes and by myelocytes in marrow and leukæmic blood. Mastcells produce this less readily, as do some myeloblasts (non-granular myelocytes). The reaction is not given by lymphocytes or red blood cells, nor by normal tissue elements except the epitbelium of the parotid and lacrymal glands. The oxydase in myeloid cells is not destroyed by the paraffin process; sections are best preserved in water-glass. It is soon destroyed by hydrochloric and oxalic acids, sublimate, picric acid, and phenol, but not by formalin, hydrocyanic acid, osmic acid, or resorcin. The reaction is of great assistance in determining the distribution of myeloid tissue. W. M. Scott (Edinburgb) gives an admirable summary of the present knowledge of a difficult subject in his paper, Anaphylaxis in the Rabbit; the Mechanism of the Symptoms. Rabbits may be sensitised to foreign serum or blood corpuscles, milk, bacteria, or vegetable proteins. The dose required is much larger than where guinea-pigs are used; the sensitive state develops after ten days, lasts another ten days, and then rapidly declines. If the animal survives an anaphylactic shock it is refractory for about four days and fully sensitive again on the serenth day. Passive transference of the sensitive condition is best effected if the serum from a sensitised animal and the foreign protein are injected into $\mathbf{a}$ fresh animal simultaneously. There is a great variation in the degree to which individual rabbits can be sensitised; this varies with the amount of precipitin developed in their serum. The prostration and muscular paresis of the anaphylactic shock are due to a great fall of blood pressure; the portal area is intensely congested; and there is paralysis of the capillaries as well as the arterioles. The arrest of respiration is due to commencing cedema of the lungs. In the blood there are delayed coagulation and imperfect fibrin formation, a marked leucopenia ; precipitin disappears completely from the serum and complement is much diminished; bacteriolytic and opsonic powers are decreased. There is some evidence of injury to the endothelium of the bloodvessels. The author attributes the anaphylactic illness to the interaction of precipitin and antigen; there is no precipitin for several days after recovery, and when it reappears the animal again becomes sensitive. The rectal temperature falls during the illness, and the gaseous exchange is diminished by about 25 per cent. Under the title Syphilis of the Lungs, with the Report of a Case, A. R. Robertson (Harvard) describes a case showing multiple gummata in the middle and lower lobes of both lungs with syphilitic aortitis and an aneurysm of the aorta. No spirochætæ could be found in either aorta or lung. J. Lorrain Smith (Manchester) continues to report observations on the Staining of Fat by Nile-blue Sulpkate. Criticising Pappenheim and others who have supposed that the red colour in which Nile-blue stains neutral fat is due to metachromatism, he points out that this is incorrect. Watery solutions of Nile-blue sulphate stain fat or fatty acids red because they contain the oxazone which has arisen by oxidation of the oxazine base; they stain fatty acids blue because the colour base (oxazine) unites with the fatty acid to form a blue soap-like compound. He thinks that confusion has arisen because the oxazone and the oxazine base are both red substances and that both stain fat red because they are more soluble in fat than in the dye solution.
(Edinburgb), in an interesting paper, discusses the Resistance of Human Red Blood Corpuscles in Health and Disease to Hæmolysis by Saponin; with a Cor parison of Saponin and Hypotonic Salt Solution Hæmolysis. He investigated the hæmolytic effect of saponin on washed red cells suspended in 0.85 per cent. salt solution at $37^{\circ} \mathrm{C}$; the degree of hæmolysis was measured by using a uniform dose of red cells $(50,000,000)$ and counting the number left undissolved at the end of the experiment. He finds that the resistance is diminished in jaundice, anæmia, and high fever; in diabetes it is increased. The resistance to hypotonic salt solution is increased in jaundice and diminished in anæmia. Experiments in vitro show that red cells kept for some time in a slightly hypertonic salt solution develop a much increased resistance to hæmolysis by hypotonic solutions $(0.42$ per cent. $\mathrm{NaCl})$, their resistance to saponin remaining unchanged. The high resistance to hypotonic bæmolysis in jaundice is due to the plasma being somewhat hypertonic; the low resistance to saponin hæmolysis to the bile salts having combined with some of the lipoids of the red cell envelope. W. B. M. Martin (Glasgow) contributes an article on the Gonococcus and its Differentiation from Allied Organisms. He contends that the reaction of the medium is most important when the gonococcus has to be cultivated. To a beef broth are added 0.5 per cent. disodium phosphate (NaHPO), 1 per cent. peptone, and 2 per cert. agar ; the reaction is adjusted to 0.6 per cent. acid to phenolphthalein (titrated hot). On to the surface of a sloped tube are run three or four drops of sterile human serum which has been heated to $57^{\circ} \mathrm{C}$. for one and a half hours. On this medium gonococci grow readily. They are easily killed by cold, and it is therefore of great importance to make the cultures direct from the living bodies and to transfer to the incubator as soon as possible. Descriptions are given of the cultural appearances of gonococcus, meningococcus, and M. catarrhalis. The author finds that the ferment actions on dextrose, lævulose, maltose, and cane sugar afford important and useful differential tests. Complement deviation and bactericidal action with immune animal sera are also of service in diagnosis. The three organisms are undoubtedly distinct, though doubtful strains are sometimes met with. Abstracts of an interesting series of papers contributed as the Proceedings of the Pathological Society of Great Britain and Ireland complete a valuable number.

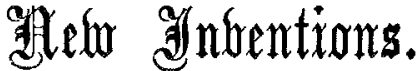

\section{NEW MEDICATED VAPOUR APPARATUS.}

A NEW hot-air and hot medicated vapour apparatus has been made for me by the Sanitas Electrical Company, Limited, of New Cavendish-street, London, W., which I have found extremely useful in the treatment of chronic suppuration in the middle ear, in the antrum of Highmore, and in the frontal sinus. As will be seen from the accompanying illustration, it consists of a small cylinder $A, 1 \frac{3}{4}$ inches long and 1 inch diameter, fixed on a handle. On one side of this is a small mica window, through which the amount of heat produced in the coils of wire contained in the cylinder can be determined by watching the glow produced, from dull to bright red. At $B$ is the inlet tube through which either air or medicated vapour is passed, and at $C$ is the outlet tube. At $D$ are the terminals connected with the wire coils, which can be attached either to a Multostat or to any accumulator working a cautery.

The following are the advantages possessed by this little instrument: It is extremely light-4 ounces with cords attached. It can be used either for hot air or for hot 
medicated vapours-e.g., formalin, creasote, carbolic acid, \&c. The heat is under perfect control, as is also the amount of air or vapour given. The hot air or medicated vapour can be given equally well through the external auditory meatus,

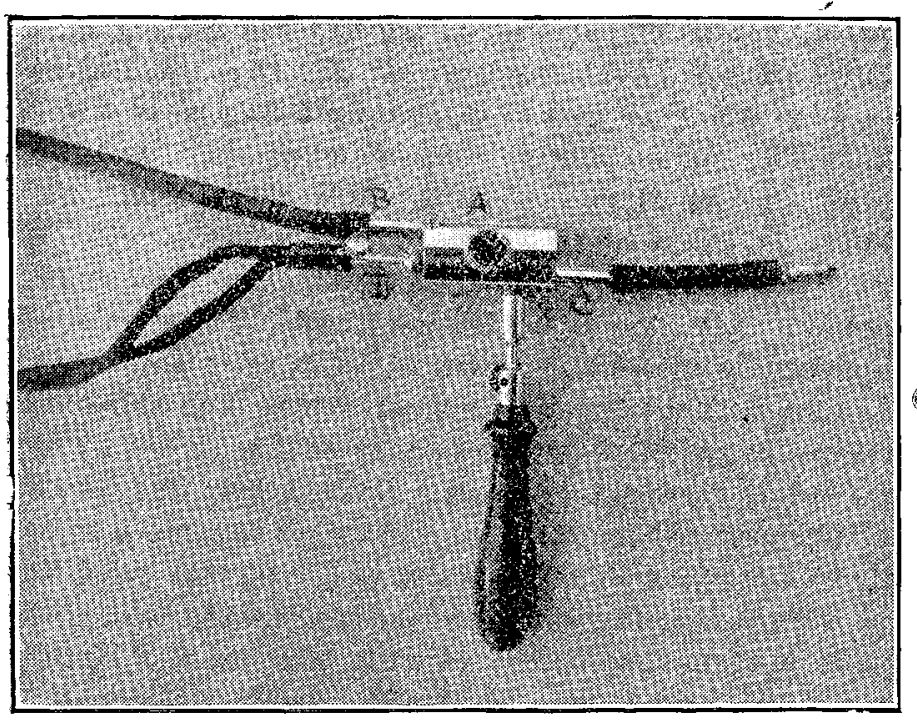

the Eustachian catheter, the frontal sinus catheter, or through a Lichtwitz's cannula into the antrum of Highmore. The price of the instrument is £2 10 s.

J. GAY French, M.S. Lond., F.R.C.S. Eng.

Harley-street, W.

\section{THE LONDON COUNTY COUNCIL AND MEDICAI AFFAIRS.}

AT the meeting of the Education Committee of the London County Council on Dec. 14th the receipt of two letters from the Board of Education was reported-one with reference to the Council's reply to the Board's criticisms of the arrangements for medical inspection in the metropolis, ${ }^{1}$ and the other on the proposals for making a first experiment in dental treatment at the Deptford Children's Centre and the Poplar Hospital for Accidents.

\section{The Reorganised Scheme of Medical Inspeotion.}

With regard to the Council's reorganised scheme of medical inspection, the Board remarked that the question whether the arrangements were adequate and satisfactory was one which could not be considered merely in relation to the number of officers employed and the number of inspections which each officer might be able to carry out, and the Board was not yet in a position to express any considered opinion on the question. The Board reminded the Council that its investigations had disclosed a great lack of that organisation, direction, and control of the medical staff which was essential in dealing with the enormous area and numbers involved in the case of London schools, and particularly when the work was attempted by means of part-time school medical officers. The Board could not find in the Council's reply to its previous criticisms any clear indication of the means by which the Council was remedying, or was proposing to remedy, these defects The effectiveness of the increased staff described must depend upon the instructions under which the scheme was worked henceforward and the manner in which those instructions were observed in practice. The Board presumed, though this was not stated, that detailed instructions had been given already by the principal school medical officer to secure that the work of inspection was being regularly and continuously carried out on a definite system designed to cover the ground effectively, and that such a system was in actual operation all over London. The Board could only express the hope that when the working of the new arrangements came to be examined it would be found that the urgent needs of the

1 Tre LanCet, Nov. 5th, 1919, p. 1364. metropolis in respect of medical inspection had been adequately provided for at last.

The Experiments in Dental Treatment.

With regard to the proposals for dental treatment, the Board wrote that, while it recognised it was essential to proceed tentatively in attacking the problems with which the Council was confronted in the sphere of medical treatment, there existed an obvious and relatively pressing need that some early action should be taken to deal with those defects which seriously threatened the physical welfare of the children. The Board had been willing, therefore, to sanction certain experimerts in the matter of medical treatment. It was necessary, however, that the Council should understand that the Board now felt it imperative to adopt a more critical attitude in regard to the Council's proposals, and, in particular, that the time was approaching when it would be unable to sanction the adoption of further schemes, even on an experimental basis, unless each particular scheme of treatment proposed had been (a) carefully thought out as regards all important details; (b) was so framed as to furnish full and definite information on the particular matters with which the experiment was concerned; and (c) had been devised so as not to hamper or embarrass the local authority in adopting any com. prehensive system of treatment which might commend itself to it in the future. The Board could not too strongly impress on the Council that any satisfactory system of treat ment, of necessity, must rest and be contingent upon adequate arrangements, in real working order, for regular medical inspection. As regards the proposals now in question the Board had considerable doubt whether the three conditions just laid down were satisfied even approximately. For instance, it was doubtful whether the Council, in deciding to apply the dental treatment scheme to children of 8 to 9 , had selected the most appropriate age-group for conservative dental treatment. The Board noted, of course, that one of the Council's reasons for selecting this group was that arrangements were contemplated for the general medical inspection of children at this period, and that it was expected that the school doctors would be able then to select children for dental treatment. For two reasons, however, the Board doubted the wisdom of basing dental treatment upon the general medical inspection of a third age-group. In the first place, it might prove impossible for the authority to inspect this group in addition to entrants and leavers. The latter was compulsory, but the optional inspection might have to be postponed or only partially carried out. In the second place, experience showed that the findings of school doctors engaged in general inspection could not be adopted in any considerable degree as the basis for arrangements for conservative dental treatment. Reliance on this source of information involved risk of embarrassment and early confusion in the working of the scheme, and a probable failure to discover many cases which needed, and would repay, conservative treatment.

In view of these and other considerations the Board had hesitated to sanction the two proposals now before it, and the Council must not expect that the Board would be prepared to sanction for general or permanent adoption a scheme of dental treatment framed on the lines of these proposals. As they were limited in scope, of local application only, and admittedly put forward as tentative and experimental, the Board had decided to sanction the proposals, since at this juncture it was reluctant to interpose obstacles to any scheme which, however imperfect, offered a prospect of furnishing data for the Council's future guidance. This sanction would be for 12 months and was subject to facilities of inspection being afforded to the Board's medical officers and to a report by the Council upon the general working of the schemes.

The Recommendations of the Royal Commission on the Feeblemended in Relation to Lunacy Admrnistration in London.

Debate on this matter was postponed last week in order that opportunity might be afforded for discussion when members absent on election business could be present. But the London County Council on Dec. 13th passed the whole of the recommendations of the General Purposes Committee ${ }^{2}$ without further consideration. 